\title{
Worth more dead than alive
}

\section{Should we attempt to conserve biodiversity simply for its own sake?}

\section{Requiem for Nature \\ by John Terborgh \\ Island Press: 1999.656 pp. $\$ 24.95$}

\section{Harold A. Mooney}

John Terborgh has written a dispiriting book. He paints a grim picture of the current status and prognosis for tropical-forest ecosystems. His bottom line is that attempts by both local and international groups to deal with the conservation of natural tropical-forest ecosystems are not working and, in some cases, are acting against the long-term viability of the few preserves that exist. Given that the only solution Terborgh suggests will seem impractical to most, or at least unachievable in the time we have to save what exists, Requiem for Nature leaves the reader feeling quite hopeless.

What has led Terborgh to such conclusions? He carefully lays out his credentials as a long-term observer of the status of tropical parks, particularly those in Peru but also in other parts of the tropical world. What he has seen is the steady erosion of the integrity of preserves as population pressures build up around them, coupled with a lack of institutional capacity to deal with local threats to the wildlife. Further, Terborgh has documented the large areas that are needed to maintain top predators in tropical forests, and finds that these are often much larger than the sizes of preserves. And he has shown the substantial consequences that the loss of these predators will have for the dynamics of forest ecosystems.

What does Terborgh think we should be preserving? He states that the concept of biodiversity embodied in the Convention on Biological Diversity is too broad (genes to ecosystems), and that we should focus on species. However, he then notes that it is actually species interaction (the web of interactions) that we should be preserving, which would encompass the higher-level species. He doesn't think the human species should be part of these interactions, and certainly not part of the parks.

Terborgh's strong message is that we should be conserving biodiversity for its own sake and not for any utilitarian value, and that arguments for conservation "must be spiritual and aesthetic". He makes this point to counter conservation efforts that have been based on the potential economic return to be obtained from intact forests through their exploration for medicines and other products, or the development of ecotourism. He states that these money-generating activities will be insufficient to save the tropical forests and that, to use his catchiest phrase, these forests are "worth more dead than alive". No doubt this assertion will cause considerable consternation among conservationists. Terborgh does not evaluate, or even discuss, the concept of ecosystem services and how they might play into the conservation equation. However, it would be hard to do this within the context of the inefficient social systems that he attributes to many of the developing countries in which the tropical parks lie.

The book produces some compelling figures: 50 per cent of the world's biodiversity is contained in only seven per cent of the Earth's land surface that constitutes tropical forests. Only eight per cent of these forests are protected, at least on paper. Terborgh's point is that these park designations do not give a real sense of their lack of protection. $\mathrm{He}$

notes that the area of park needed to support viable populations of some of the top predators in these systems is about one million hectares. Few parks are this large. According to conservative estimates, the last tropical old growth, apart from that in parks, will be gone by the middle of this century, making park size and integrity an even more pressing concern.

So what is Terborgh's answer? First, we must do something about the forces that are confounding conservation efforts - "overpopulation, inequities of power and wealth, exhaustion of natural resources, corruption, lawlessness, poverty and social unrest". More directly, we need to design better protection for the parks. Terborgh holds the US park service up as a model of what is needed: welltrained people who know the parks and have

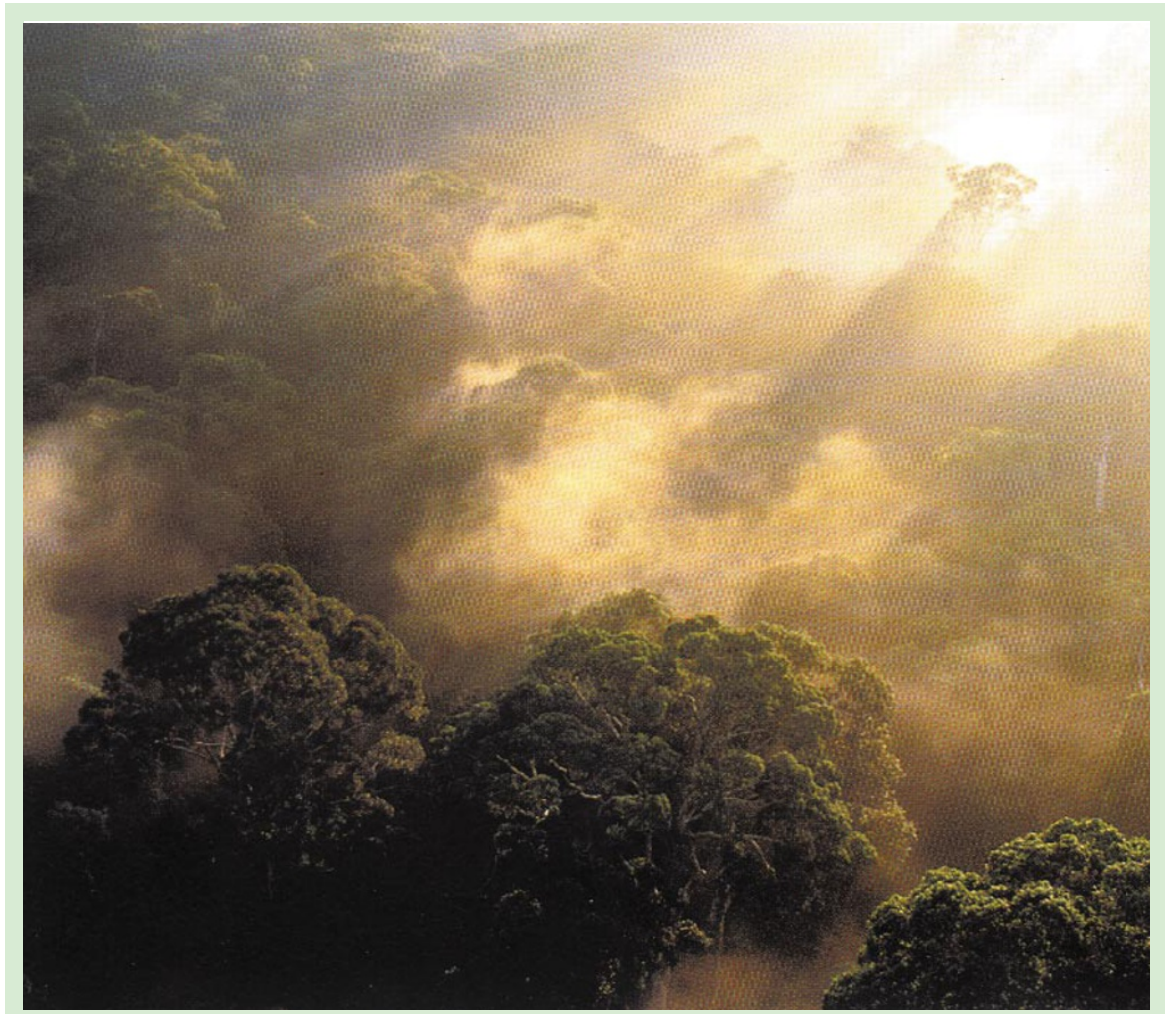

\section{A receding wilderness}

Indonesia's expanding logging industry is decimating the lowland rainforests of Sumatra and Borneo (shown above). The lavishly illustrated Archipelago: The Islands of Indonesia, From the Nineteenth-Century Discoveries of Alfred Russel Wallace to the Fate of Forests and Reefs in the Twenty-First Century by Gavan Daws and Marty Fujita (University of California Press, \$45, £27.50) describes the 14,000-mile journey made by the naturalist Alfred Russel Wallace among these islands - it was while on the archipelago that, independently of Charles Darwin, Wallace developed a theory of evolution by natural selection. The book's final chapter looks at twentieth-century Indonesia and the ravages to biodiversity that have been wrought by the country's economic imperatives. 
the authority to protect them, combined with a budget to do this and a human population that values their existence.

Terborgh believes that this model cannot be achieved with the current pressures of populations and the social systems that prevail in many of the tropical nations. He feels that stewardship and management of natural systems cannot be left in the hands of the local people in most of these regions. He proposes instead a top-down effort, a sort of UN nature-keeping force, to staff the tropical parks in those countries where there is still the possibility of saving something.

This is pretty radical stuff, and is diametrically opposed to many efforts that are taking 'the village' as the fundamental conservation unit and building upwards, using local knowledge and needs.

It is interesting to compare Terborgh's position with that of Daniel Janzen, another distinguished ecologist who has had a roughly comparable career. Both Janzen and Terborgh have dedicated much of their careers to on-the-ground study of tropical forests. Each spends part of every year engaged in research in their respective study regions. Janzen has come to the view that "humanity now owns life on Earth. It plans the world, albeit with an unintended here and an uninformed there." He is looking towards human coexistence with nature rather than human exclusion, which would, in his view, lose the very things we are trying to protect.

Janzen has asked how we can most responsibly fulfil this management charge. He has become a gardener of natural systems, working towards their restoration and nurturing their diversity. To do this, he has engaged and energized local people, working towards his view of sustainability using many constituent parts. The viewpoints of Terborgh and Janzen could not be more different in spite of their similar experience.

Terborgh has focused on a remote, wet, tropical reserve in Peru, whereas Janzen has worked most extensively in a tropical dry forest in Costa Rica, a system that has been largely transformed by human activity. These differences could certainly lead to different viewpoints. Further, not only are the ecological systems in which they work different, but, as noted by Terborgh, Costa Rica is a model of what can be done for conservation by local governments in developing countries. He holds out less hope for most other tropical countries.

Most of us will stand in the wide middle ground between the approaches of Janzen and Terborgh. It is important, however, to have the Terborgh and Janzen signposts to help us gauge how successfully we are moving forward.

Harold A. Mooney is in the Department of Biological Sciences, Stanford University, Stanford, California 94306, USA.

\section{Population genetics revisited}

\section{Mathematics of Evolution}

by Fred Hoyle

Acorn Enterprises: 1999. 163 pp. \$36

John Maynard Smith

In 1987, just 100 facsimile copies of this book were produced. The book has now been typeset and made available to a wider audience, with a new preface by the author. In it, Fred Hoyle rediscovers many of the classical results of population genetics. Although he has already read Ronald Fisher, J. B. S. Haldane, Sewall Wright and Motoo Kimura, Hoyle has clearly rediscovered some of the main results. This is apparent from some of the less familiar ideas that he reports: for example, Müller's ratchet, Orgel's catastrophe theory of ageing and, more relevant to Hoyle's main thesis, the idea that a favourable mutation is unlikely to become established in a population unless genetic recombination occurs in the face of recurrent deleterious mutations - a point made in more detail by Joel Peck.

Has Hoyle reached other correct conclusions that are also new? This question is difficult to answer, because the book carries few references explaining which of Hoyle's findings are new, and which are merely confirmations of findings by others. However, I did spend some time on one particular topic, to which Hoyle devotes a whole chapter. This is the notion of a "cost of selection" associated with the establishment of a favourable mutation, of which he says "the claims are illusions". If true, this would be important. The idea of a cost originated with Haldane, who calculated that the number of individuals that must die selectively during the establishment of a favourable mutation lies between 10 and 100 times the population size.

Kimura used this as an argument for the neutral theory of molecular evolution. In effect, he estimated the rate at which molecular changes have occurred during evolution, and argued that the total cost of bringing about such changes was greater than the population could bear. He therefore concluded that most of the changes must be selectively neutral. My own contribution to the debate was to point out that Kimura's conclusion depends on the assumption that the costs associated with different genes can be added. This is correct if the effects of genes on fitness are independent, so that fitness effects are multiplicative. If gene effects are synergistic, the total cost is much lower.

When I first read Hoyle's discussion of this topic, I wondered whether he had rediscovered my objection, but this is not so. He does not object to the additivity of costs; it is the cost of a single substitution that he regards as an illusion. I am baffled by what he says. I can see nothing wrong with the algebra, but the conclusion that costs are an illusion does not follow from it - it is merely an assertion. I may be mistaken, and so I hope others will look at Hoyle's argument. But my attempt to find something novel and true in his book has therefore failed. Others, however, might profitably look for nuggets of gold. After all, when Manfred Eigen and Peter Schuster reinvented evolution by natural selection, they came up with the novel and important idea of an error threshold. Hoyle is a very clever and creative scientist; it would be surprising if he has laboured entirely in vain.

Above all, however, Hoyle reaches an unjustified and ridiculous conclusion. $\mathrm{He}$ accepts that, given genetic recombination, natural selection can produce detailed adaptation of species to their ways of life. But he argues that it cannot be responsible for the major changes required for the emergence of new orders, classes or phyla. Something else is therefore needed. This, Hoyle asserts, is the introduction of new genetic material from outer space. He is not suggesting merely that life was first seeded on Earth from space the theory of panspermia - an idea I find unappealing but not irrational. Hoyle argues for a continuing process of introduction.

He claims that the origin of new major groups is impossible without such intervention because, "What mutations cannot do is to find improvements which demand the simultaneous change of several base pairs". Evolutionary biologists would agree that a change requiring a number of base changes, each of which is without value until all are present, cannot occur by natural selection. They have therefore concluded that the origin of major groups has been a stepwise process, with each genetic change being an advantage on its own (although they would probably mention symbiosis as an exception). If there is no stepwise path up the mountain, natural selection won't climb it. Much thought has been given to the nature of the intermediate steps.

Hoyle gives no reason why such intermediate steps could not have existed; it is merely an assertion. In his preface, it is clear that he does not actually believe it. He says his preferred scenario is that "all genes in present day organisms were here already in the metazoans that invaded the Earth 57 million years ago at the beginning of the Cambrian era, making the subsequent story of terrestrial evolution into one in which genes have been called into operation as ecologic conditions permitted them to be so". Thus, most of these genes would have remained unexpressed because they would have been useless until appropriate conditions arose. Hoyle accepts that unexpressed genes would accumulate damage, but argues that, if populations were large enough, the deleterious mutations would not be fixed. Therefore, 